\title{
Subglacial roughness of the former Barents Sea ice sheet
}

\author{
E. Gudlaugsson, ${ }^{1}$ A. Humbert, ${ }^{2}$ M. Winsborrow, ${ }^{3}$ and K. Andreassen ${ }^{1,4}$ \\ Received 13 January 2013; revised 12 November 2013; accepted 18 November 2013; published 20 December 2013.
}

[1] The roughness of a glacier bed has high importance for the estimation of the sliding velocity and can also provide valuable insights into the dynamics and history of ice sheets, depending on scale. Measurement of basal properties in present-day ice sheets is restricted to ground-penetrating radar and seismics, with surveys retrieving relatively coarse data sets. Deglaciated areas, like the Barents Sea, can be surveyed by shipborne 2-D and 3-D seismics and multibeam sonar and provide the possibility of studying the basal roughness of former ice sheets and ice streams with high resolution. Here, for the first time, we quantify the subglacial roughness of the former Barents Sea ice sheet by estimating the spectral roughness of the basal topography. We also make deductions about the past flow directions by investigating how the roughness varies along a 2-D line as the orientation of the line changes. Lastly, we investigate how the estimated basal roughness is affected by the resolution of the basal topography data set by comparing the spectral roughness along a cross section using various sampling intervals. We find that the roughness typically varies on a similar scale as for other previously marine-inundated areas in West Antarctica, with subglacial troughs having very low roughness, consistent with fast ice flow and high rates of basal erosion. The resolution of the data set seems to be of minor importance when comparing roughness indices calculated with a fixed profile length. A strong dependence on track orientation is shown for all wavelengths, with profiles having higher roughness across former flow directions than along them.

Citation: Gudlaugsson, E., A. Humbert, M. Winsborrow, and K. Andreassen (2013), Subglacial roughness of the former Barents Sea ice sheet, J. Geophys. Res. Earth Surf., 118, 2546-2556, doi:10.1002/2013JF002714.

\section{Introduction}

[2] The motion of ice sheets and glaciers is resisted by forces acting at the base of the ice. The degree of coupling between the bed and the ice is controlled by bed roughness and subglacial water pressure. At relatively small vertical scales, (approximately $<1 \mathrm{~m}$ ), bed roughness is an important parameter for the estimation of the sliding velocity. At larger scales (approximately $>1 \mathrm{~m}$ ), it can give important insights into the dynamics and history of ice sheets [Bingham and Siegert, 2009] and potentially be a valuable tool in identification and analysis of subglacial bed forms.

[3] The study of subglacial roughness was originally motivated by the study of subglacial sliding, which dates back to 1957 when Weertman [1957] proposed a twomechanism theory for subglacial sliding. According to Weertman, basal ice at the pressure melting point moves

\footnotetext{
${ }^{1}$ Department of Geology, University of Tromsø, Tromsø, Norway.

${ }^{2}$ Section of Glaciology, Alfred Wegener Institute Helmholtz Center for Polar and Marine Research, Bremerhaven, Germany.

${ }^{3}$ Statoil ASA, Harstad, Norway.

${ }^{4}$ Centre of Excellence for Arctic Gas Hydrate, Environment and Climate, University of Tromsø, Tromsø, Norway.

Corresponding author: E. Gudlaugsson, Department of Geology, University of Tromsø, Dramsveien 201, NO-9037 Tromsø, Norway. (eythor.gudlaugsson@uit.no)

(C)2013. American Geophysical Union. All Rights Reserved. 2169-9003/13/10.1002/2013JF002714
}

either by regelation or by enhanced creep where the ice deforms plastically around obstacles in its path. These two mechanisms operate at different length scales, regelation operating more efficiently at the submeter scale and enhanced creep at the suprameter scale. Kamb [1970] and Nye [1970] built on his theory and, assuming a bed geometry comprising of superimposed sinusoids, included a continuous spectrum of obstacle sizes as opposed to the discrete one assumed in Weertman's analysis. They concluded that the roughness of a glacier bed could be described in terms of the power spectrum of the bed elevation. Both studies concluded that a certain controlling obstacle size exists where erosion is at a maximum and sliding velocity at a minimum, typically on the order of tens of centimeters. Fowler [1979, 1981] and later Gudmundsson [1997a, 1997b] suggested that for largescale flow, regelation could be ignored and that most of the resistance to the flow came from larger obstacles through enhanced creep.

[4] One of the first studies ever published on the spectral roughness of a glacier bed and also the only study ever to have used data measured directly on the ground was made by Hubbard et al. [2000]. They combined measurements with a microroughness meter and an electro-optical distance meter to generate composite roughness spectra over almost 5 orders of magnitude in the frequency domain. Following the theoretical analysis of Nye, they defined their total roughness index as the integral of the raw power spectra over the wave numbers. Taylor et al. [2004] followed by outlining 


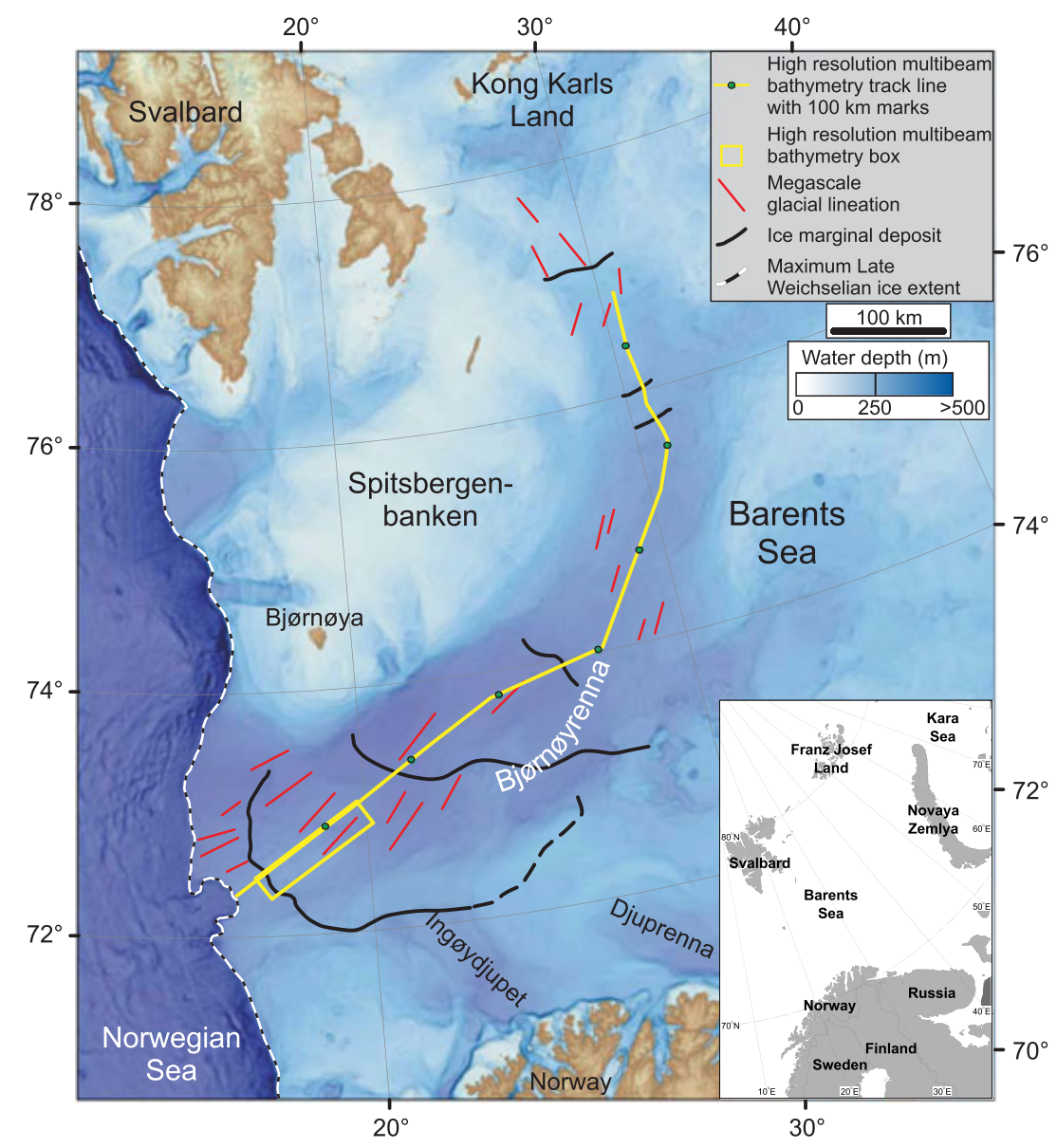

Figure 1. Bathymetry of the Barents Sea with identified ice-marginal deposits (black solid lines) and mega-scale glacial lineations (red solid lines) from Winsborrow et al. [2010]. Locations of high-resolution multibeam data used in this paper are indicated by yellow lines with green dots representing locations of the $100 \mathrm{~km}$ marks in subsequent line plots. The maximum Late Weichselian ice extent [Svendsen et al., 2004b] is marked with a white stippled line. Black and white inset shows the broader location of the Barents Sea.

a general method for estimating the spectral roughness of any bed beneath an ice mass. Their method applies to any geophysical survey with topographic data, allowing comparison between different studies as long as the methodological parameters remain the same.

[5] Several authors have applied spectral roughness analysis to various sites in Antarctica, using radio echo sounding (RES) data. Siegert et al. [2005] correlated bed roughness with ice temperature at the base of Ridge B, Dome A, and Dome $\mathrm{C}$ in Antarctica, noting that beds which are rough at all scales tend to be overlain by ice which is frozen to the bed. Bingham and Siegert [2009] correlated low basal roughness for previously marine-inundated areas of the bed beneath the West Antarctic ice sheet (WAIS), with the presence of weak marine sediments facilitating ice flow. Rippin et al. [2011] investigated the relationship between ice velocity and basal roughness for Pine Island Glacier and also correlated smooth areas with deposits of marine sediments.

[6] Analyses of bed roughness offer the exciting potential to quantitatively compare contemporary subglacial landscapes and Quaternary glaciated landscapes, an important tool in improving our understanding of landscape evolution and glacial thermal regimes. As a contribution toward such work, this paper presents results from the first study of continental scale bed roughness across a Quaternary glaciated landscape: the bed of the former Barents Sea ice sheet (BSIS). As opposed to the RES data sets used in most previous studies, this study uses seismic and multibeam bathymetric data sets. The greater data coverage and better resolution of such data sets provide a unique opportunity to investigate roughness over a much larger part of the bed, across a wider range of scales and range of orientations relative to ice flow direction. In addition to characterizing the bed roughness of the BSIS, we investigate the impact of varying the resolution and the moving window length on the calculated roughness, as well as examining the effect of varying track orientations, something which is not possible with RES data sets from contemporary ice sheets. Varying track orientations allows for a rough estimation of former flow directions. In previous work, estimation of the angle dependence has been restricted to differences in roughness at track line crossover points, whereas our data set allows us to extract roughness along all directions. In comparing our results of a Quaternary glaciated landscape to the results of similar analyses done for modern subglacial environments in Antarctica, we are able to draw conclusions 


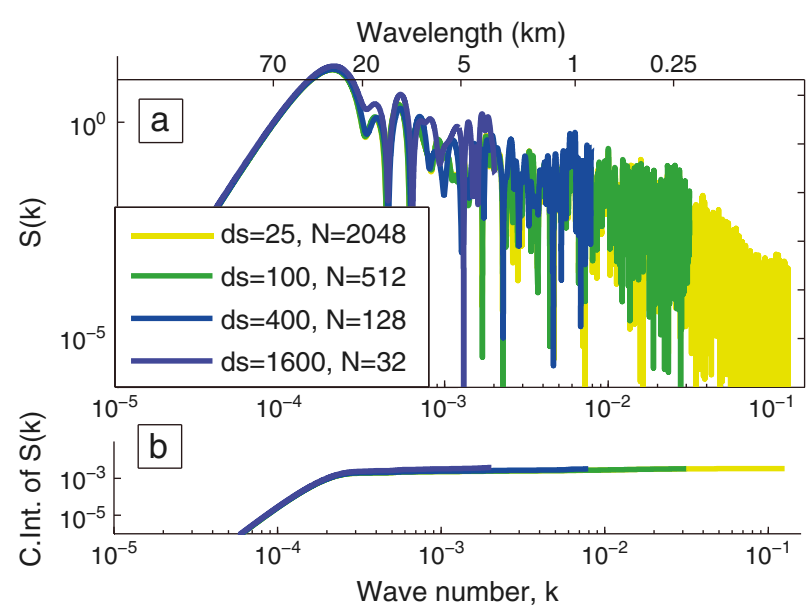

Figure 2. Examples of power spectra for a MW of a fixed length $(L \approx 50 \mathrm{~km}$ ), with varying resolutions. (a) Power spectra. (b) Cumulative integral of the power spectra over wave number. $d s$ stands for the distance between datapoints in meters and $N$ for the number of datapoints.

about the subglacial environment of the former BSIS and the characteristic roughness signature of common subglacial landforms/ice flow regimes, the first steps toward developing a quantitative scheme to characterize subglacial landscapes both contemporary and Quaternary.

\section{The Barents Sea}

[7] The Barents Sea (BS, Figure 1) covers one of the widest continental shelves in the world. It is bounded to the north and west by tertiary rift and shear margins, to the east by the island of Novaya Zemlya, and to the south by the Norwegian and Russian coasts. Close to the northern boundary are the islands of Svalbard and Franz Josef Land and to the east is the Kara Sea. The sea floor bathymetry is characterized by relatively shallow banks of between 100 and $200 \mathrm{~m}$ water depths separated by troughs, opening toward the Norwegian Sea and the Arctic Ocean, of water depths between 300 and $500 \mathrm{~m}$. The most prominent trough is the Bjørnøyrenna (Bear Island Trough), formerly occupied by a major ice stream [Andreassen and Winsborrow, 2009]. Separating sedimentary rocks from the overlying Quaternary sediment sequence is the upper regional unconformity representing the most significant seismic reflector in the Barents Sea. On the shelf, the sediment thickness ranges from 0 to around $300 \mathrm{~m}$. Postglacial infilling is limited, with only a thin veneer of Holocene sediments, typically less than $2 \mathrm{~m}$ [Elverhøi and Solheim, 1983; Vorren et al., 1988]. In some areas, such as on Spitsbergenbanken, the glacial sediments have been reworked by currents and mixed with Holocene bioclastics [Elverhøi and Solheim, 1983].

[8] The former BSIS offers a good geological analog to the contemporary WAIS. Similarities between the two ice sheets include a bed largely below sea level resting on sedimentary bedrock, a high-latitude position, and similar sizes during the Last Glacial Maximum (LGM) when both ice sheets were located at or near the shelf break [Svendsen et al., 2004a; Anderson et al., 2002; Evans et al., 2006]. The WAIS grounding line has in some areas retreated up to
$1000 \mathrm{~km}$ since the LGM, whereas the BSIS went through stepwise retreat with the Barents Sea largely deglaciated by $12 \mathrm{kaBP}$ [Andreassen et al., 2008; Andreassen and Winsborrow, 2009; Winsborrow et al., 2010]. A series of grounding-zone wedges and streamlined bed forms can be followed up the Bjørnøyrenna, documenting the retreat of the Bjørnøyrenna Ice Stream (Figure 1).

\section{Method}

\subsection{Roughness Calculations}

[9] Roughness is, in general, defined as a relative measure of the degree of irregularity in a surface. The methodology used in this paper follows Taylor et al. [2004] and uses a fast Fourier transform (FFT) to convert bed elevations into wavelength spectra. The procedure is applicable, in principle, to any geophysical track line data, as long as the data are of sufficient quality. The FFT requires a fixed spatial sampling interval. Most geophysical data sets have a fixed sampling interval with respect to time so the data have to be interpolated to accommodate that requirement. Any gaps were filled by means of linear interpolation, provided that they were not too long to render that part of the profile unusable. Here we have used a maximum gap length of 7 datapoints $(175 \mathrm{~m})$. If any gap was longer than that, the profile was split into separate segments. For each point estimation of roughness, an elevation profile $Z(x)$ of a certain given length $l$, typically referred to as a moving window (MW), is used. Before passing it through the FFT, it is linearly detrended by subtracting from the raw data a best fit line $Z_{\mathrm{bf}}(x)$ through the data itself. This procedure gives a detrended elevation profile $Z_{0}(x)$ where

$$
Z_{0}(x)=Z(x)-Z_{\mathrm{bf}}(x)
$$

[10] This decreases the dominance of the very long wavelengths while the small-scale roughness remains largely

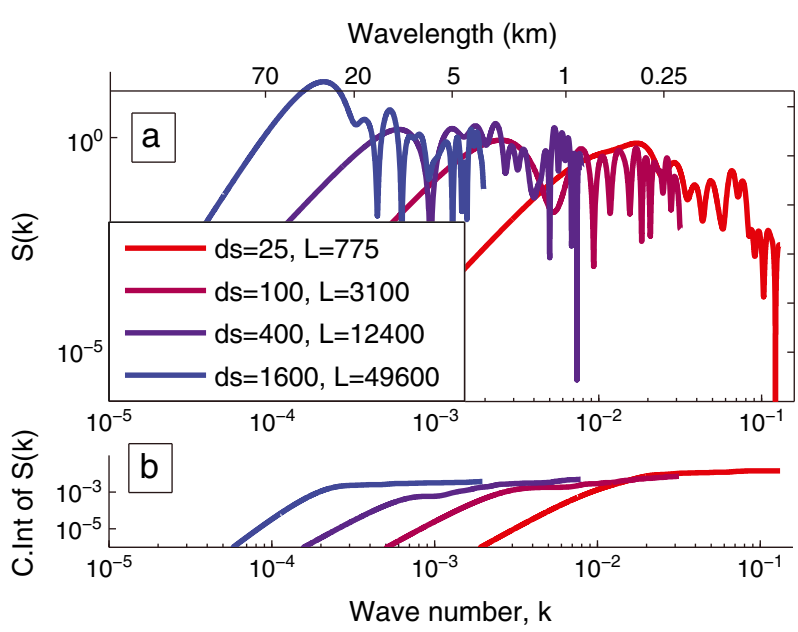

Figure 3. Examples of power spectra for a MW with a fixed number of datapoints $(N=32)$, while varying the distance between them $(d s[\mathrm{~m}])$. (a) Power spectra. (b) Cumulative integral of the power spectra over wave number. $L$ represents the length of the MW in meters. 

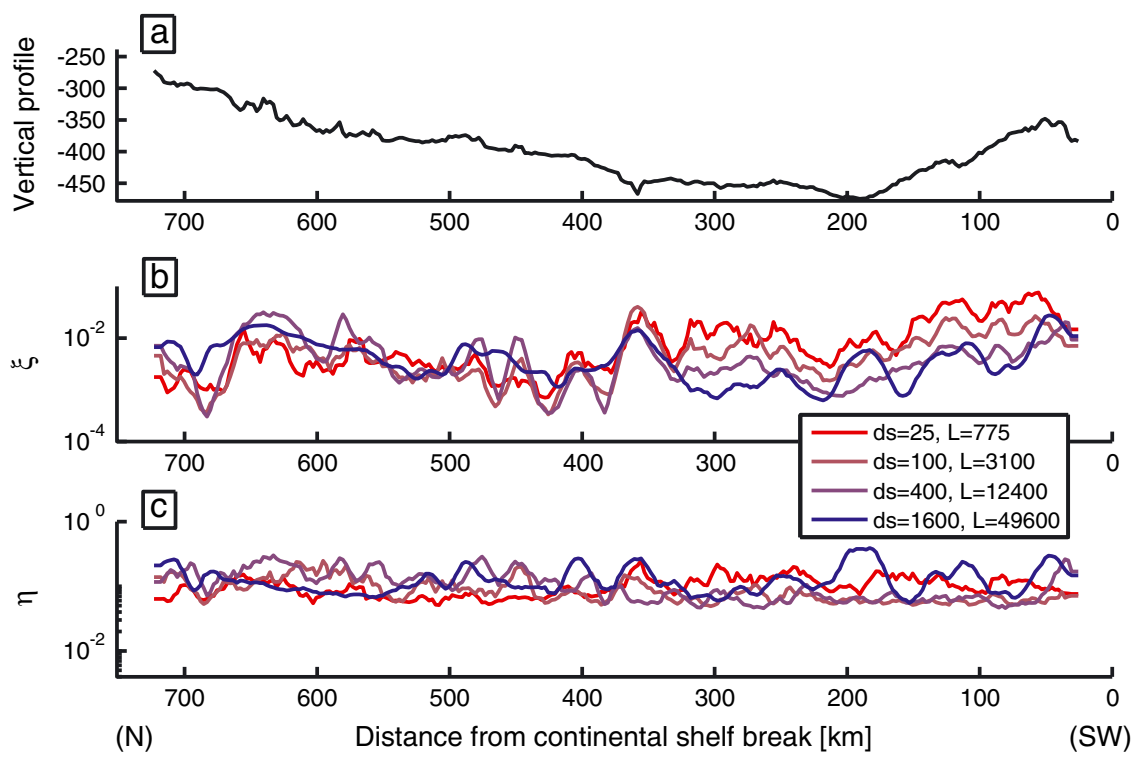

Figure 4. Roughness indices for a track line running from the south of Kong Karls Land to the SW Barents Sea continental shelf break, calculated with a fixed number of datapoints for each point estimate but varying lengths of the MW $(L[\mathrm{~m}])$. (a) Elevation profile in meters below sea level. (b) Basal roughness index. (c) $\eta$ parameter. The horizontal axis in all subfigures shows the distance in kilometers from the continental shelf break.

unaffected [Shepard et al., 2001]. Li et al. [2010] introduced a two-parameter index to describe roughness using the slope, $\operatorname{sl}(x)=\partial Z_{0} / \partial x$, of the detrended elevation profile. They showed that although calculating roughness based on the FFT of elevation profiles was a useful way of describing roughness, it might not be sufficient as it only accounts for vertical irregularities in a surface while missing the horizontal ones. They proposed using the slope profile as a link between the horizontal and the vertical undulations. The FFT is calculated for both the detrended elevation and the slope profile, using a minimum of $N=32$ data points for each $\mathrm{MW}$, and the resulting amplitudes are normalized with $N / 2$. The basal roughness index $\xi$ is then defined as the integral of the spectral power density $S(k)$ over the wave numbers $k$, where $k_{1} \rightarrow k_{2}$ is the range of wave numbers over which the integration is carried, scaled with the length of the MW (equations (2) and (3)). The second roughness parameter $\eta$ is defined as the ratio of the basal roughness index and the corresponding index $\xi_{s l}$, calculated with the slope profile (equation (4)).

$$
\begin{gathered}
S(k)=\frac{1}{l}\left|\overline{Z_{0}}(k)\right|^{2} \\
\xi=\int_{k^{1}}^{k^{2}} S(k) \mathrm{d} k \\
\eta=\frac{\xi}{\xi_{s l}}=\frac{\int_{k_{1}}^{k_{2}} S(k) \mathrm{d} k}{\int_{k_{1}}^{k_{2}} S_{s l}(k) \mathrm{d} k}=\frac{\int_{k_{1}}^{k_{2}} \frac{1}{l}\left|\overline{Z_{0}}(k)\right|^{2} \mathrm{~d} k}{\int_{k_{1}}^{k_{2}} \frac{l}{N}\left|\partial Z_{0} / \partial x\right|^{2} \mathrm{~d} k}
\end{gathered}
$$

where $\bar{Z}_{0}(k)$ is the Fourier transform of a detrended elevation profile of a given length $l, \partial Z_{0}^{-} / \partial x$ is the Fourier transform for the corresponding slope profile, and $S_{s l}(k)$ is the spectral power density for the slope profile.

[11] The basal roughness index $\xi$ reflects the vertical amplitudes of the profile, so the closer the values are to 0 , the smaller the amplitudes and the smoother the bed. The $\eta$ index represents the horizontal variation with a high value corresponding to a relative dominance of the longer wavelengths while a small value indicates a relative dominance of shorter wavelengths.

\subsection{Data and Experiments}

[12] Two different sets of data have been used. The first comprises high-resolution $(12 \mathrm{~m})$ uninterpolated multibeam bathymetry data collected by the University of Tromsø, and the second is a composite data set of the southwestern Barents Sea. The high-resolution data cover only selected areas including a track line of around $750 \mathrm{~km}$ running from the south of Kong Karls Land to the southwestern Bjørnøyrenna continental shelf break (Figure 1). This data set was gridded with a $25 \mathrm{~m}$ grid size and a single track line extracted from there. Any gaps in the track line shorter than or equal to 7 times the grid size were filled by linear interpolation. Around $1 \%$ of the datapoints from the highresolution track line were involved in interpolation, and $85 \%$ of this was performed over gap lengths of three datapoints or less.

[13] Two kinds of experiments were performed with the track line data. In the first the MW length was kept more or less constant while the number of datapoints varied between comparisons. The absolute length of each MW changes slightly with the number of datapoints $(L=d s(N-1))$ but not to such a degree as to affect the comparison in a significant way. The number of datapoints in each MW ranges from the minimum recommended value of $2^{5}=32$ [Brigham, 1988] up to $2^{11}=2048$ points, making use of the full resolution of our data set for a profile length of $50 \mathrm{~km}$. The length of the MW in the comparison thus varies with maximum 3\% between the longest and the shortest one. In the other kind of experiment that was performed, the number of datapoints for each MW was kept constant at $N=32$ while the distance between the points was progressively doubled 

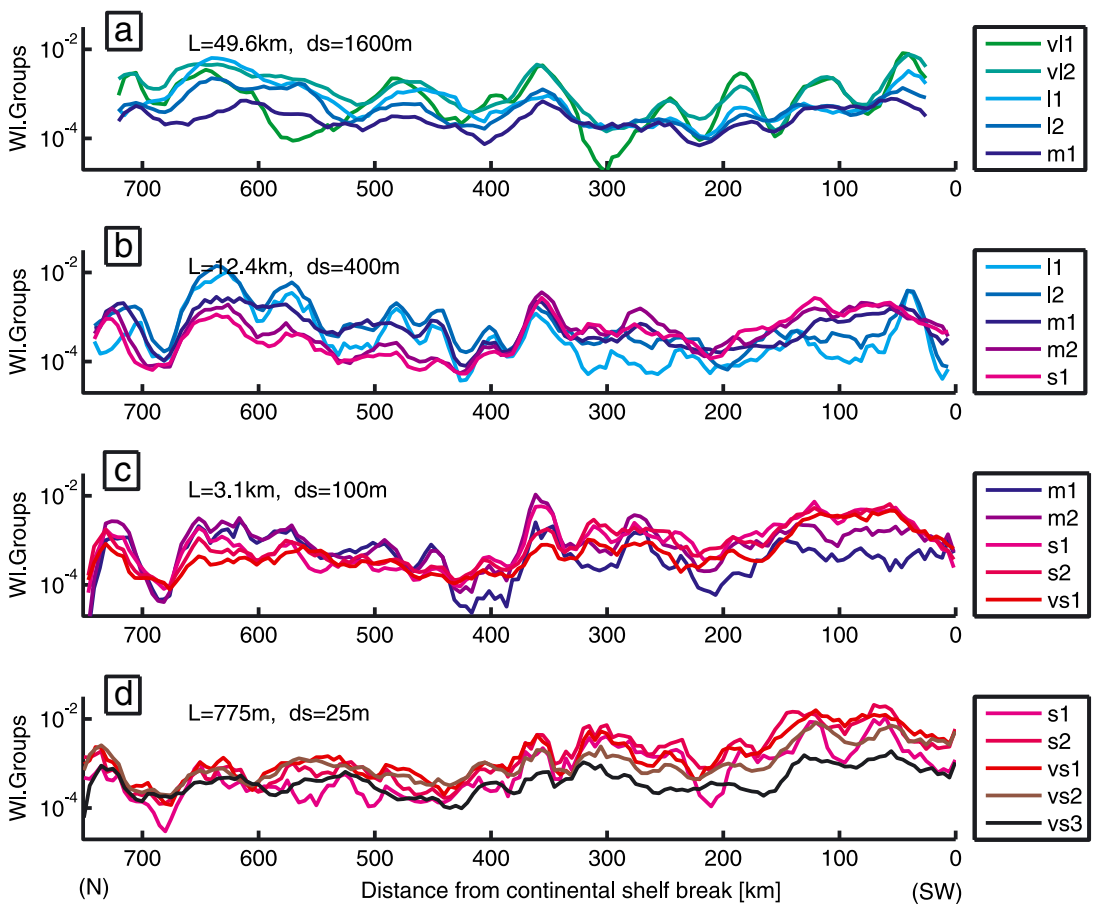

Figure 5. Wavelength components of the four basal roughness profiles $(\xi)$ presented in Figure $4 \mathrm{~b}$ and with wavelength groups defined by Table 1 . Splitting the interval of integration into several subintervals and integrating over them separately reveal which length scales are contributing the most to the basal roughness index ( $\xi$ ). (a) $L=49.6 \mathrm{~km}, d s=1600 \mathrm{~m}$, (b) $L=12.4 \mathrm{~km}, d s=400 \mathrm{~m}$, (c) $L=3.1 \mathrm{~km}$, $d s=100 \mathrm{~m}$, and (d) $L=775 \mathrm{~m}, d s=25 \mathrm{~m}$.

with each calculation. The MW length thus varied from the shortest possible one of $775 \mathrm{~m}$ to the longest one of $49.6 \mathrm{~km}$.

[14] All figures featuring results from these track line data have a horizontal axis indicating distance in kilometers from the continental shelf break and have been smoothed with a five-point moving average to improve readability. These data have been used previously to identify geomorphological features on the seafloor, such as mega-scale glacial lineations (MSGLs) and sedimentary wedges, giving information about past flow directions and grounding line positions [Rüther et al., 2011].

[15] The other data set that was used for this study was a composite data set, created from a dense grid of industry 2-D multichannel seismic data mainly covering the southwestern Barents Sea, single-beam bathymetric data (provided by the Norwegian Defense Research Establishment), and the International Bathymetric Chart of the Arctic Ocean [Jakobsson et al., 2008]. These data sets were merged to give a single bathymetric grid for the entire Barents Sea with a combined horizontal resolution of $600 \mathrm{~m}$. For the purposes of this study, we decided to limit the study area to the southwestern part of the Barents Sea where data coverage and accuracy are highest.

[16] Previous analyses indicate that subglacial roughness is generally an order of magnitude smaller parallel to ice flow direction as compared to the flow-perpendicular direction [Hubbard et al., 2000; Boulton, 1979], demonstrating clearly that there is information contained in roughness signatures that can be used to reconstruct former flow directions for deglaciated areas. The composite grid was therefore used to estimate the basal roughness and the directions for which a minimum in roughness was acquired, for the area covering the southwestern Barents Sea.

[17] Profiles of 32 datapoints were extracted from the composite grid using a profile resolution of $1600 \mathrm{~m}$, giving a final length of $\sim 50 \mathrm{~km}$. This resolution was chosen to make the resulting roughness map comparable to similar maps, already published, for various areas in Antarctica [Siegert et al., 2004; Bingham et al., 2007; Bingham and Siegert, 2007, 2009; Rippin et al., 2011] and also to minimize the influence of any iceberg ploughmarks in the area, as they then fall beneath or close to the Nyquist frequency and are therefore at the limit of detection. The profiles were extracted over a range of $\pm 90^{\circ}$ from a given reference angle and then used to investigate the orientation dependence of the spectral roughness estimate. The magnitude of orientation dependence (MOD) was quantified in two different

Table 1. Definition of Roughness Wavelengths Used in This Paper, Following Taylor et al. [2004]

\begin{tabular}{lc}
\hline Wavelength Class & Roughness Wavelength \\
\hline v11 & $>40 \mathrm{~km}$ \\
v12 & $20 \mathrm{~km}-40 \mathrm{~km}$ \\
11 & $10 \mathrm{~km}-20 \mathrm{~km}$ \\
12 & $5 \mathrm{~km}-10 \mathrm{~km}$ \\
$\mathrm{~m} 1$ & $2.5 \mathrm{~km}-5 \mathrm{~km}$ \\
$\mathrm{~m} 2$ & $1250 \mathrm{~m}-2500 \mathrm{~m}$ \\
$\mathrm{~s} 1$ & $600 \mathrm{~m}-1250 \mathrm{~m}$ \\
$\mathrm{~s} 2$ & $300 \mathrm{~m}-600 \mathrm{~m}$ \\
vs1 & $150 \mathrm{~m}-300 \mathrm{~m}$ \\
vs2 & $75 \mathrm{~m}-150 \mathrm{~m}$ \\
vs3 & $<75 \mathrm{~m}$ \\
\hline
\end{tabular}



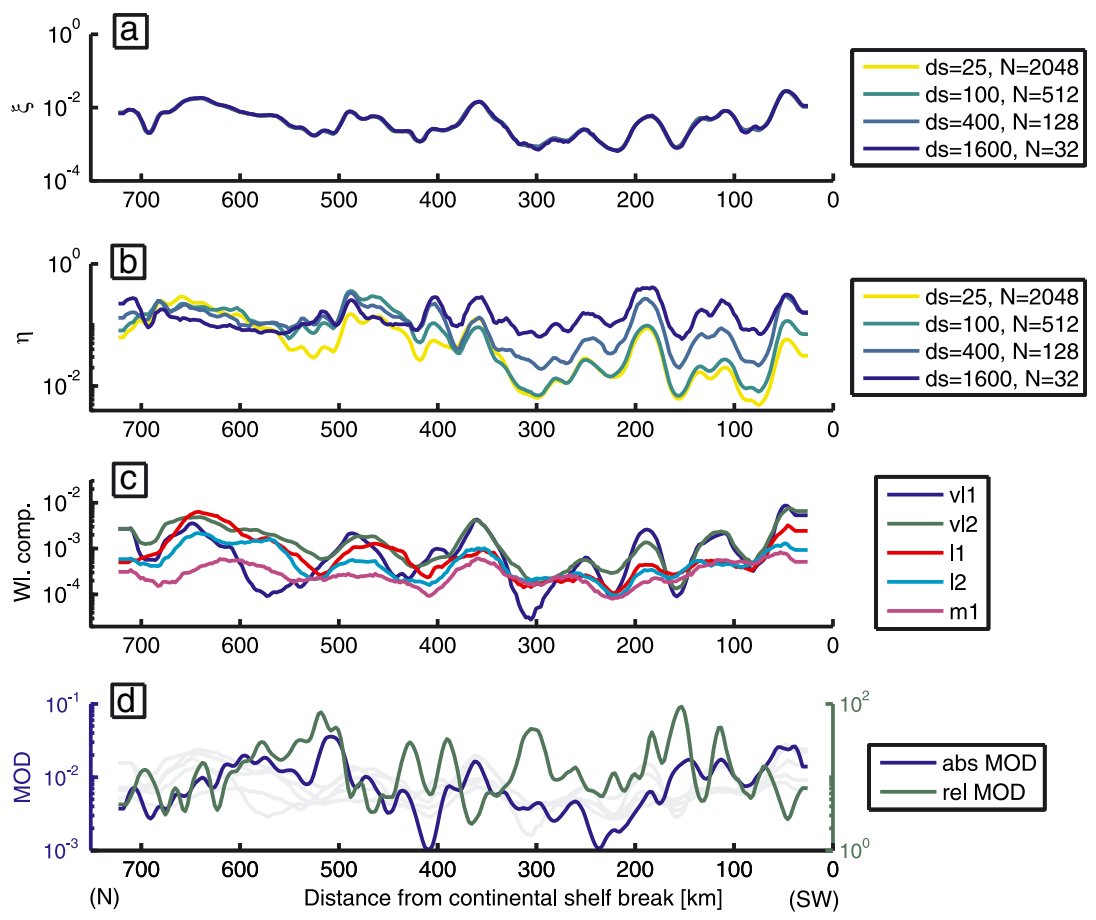

Figure 6. Roughness indices for a track line running from the south of Kong Karls Land to the continental shelf break, calculated with a fixed length of the MW $(L \approx 50 \mathrm{~km})$, varying the number of datapoints $(N)$ for each estimate. (a) Basal roughness index. Resolution makes little to no difference to the basal roughness index of the profiles. (b) $\eta$ parameter. (c) Wavelength components for the profile with $d s=1600 \mathrm{~m}$ and $N=32$ (blue line). (d) The logarithm of the magnitude of orientation dependence (MOD). The blue line represents the absolute difference between the maximum and the minimum roughness at one point while the green line represents the relative difference (the absolute difference scaled with the minimum value at each point).

ways. First, as the absolute difference between the maximum and the minimum $\xi$ roughness (abs MOD) and second as the logarithm of the ratio between the maximum and the minimum $\xi$ roughness for a single point in space along the track line (rel MOD), depending on orientation. This was done for a network of locations with a fixed spacing of $5 \mathrm{~km}$. All presented results calculated with the composite grid have been averaged over an area of $50 \times 50 \mathrm{~km}^{2}$ for clarity. The averaged minima directions then served as a basis for the final calculation of the subglacial roughness of the southwestern Barents Sea.

\section{Results}

\subsection{Effect of MW Length and Resolution}

[18] The high-resolution data were used to test how the limits of integration (equation (3)) affect the roughness estimate. Figures 2 and 3 show examples of different power spectra for a single location, chosen at random from within the high-resolution bathymetry box in Figure 1 and calculated with either different lengths of the MW and a fixed number of datapoints or by using a different number of datapoints and a fixed length of the MW. The lower part of each figure shows the cumulative integral of each case. In Figure 2, the length of the MW was kept constant at $\sim 50 \mathrm{~km}$, while the number $(N)$ and distance between datapoints $(d s)$ was varied. For each profile, the estimated

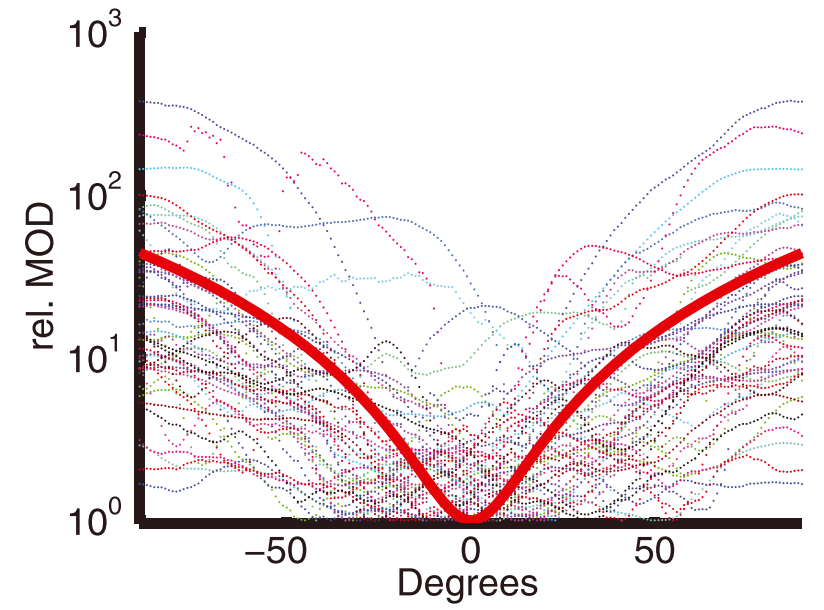

Figure 7. The $\xi$ roughness profiles as a function of orientation. All profiles have been calculated with $N=32$ and $d s=1600 \mathrm{~m}$ and then normalized with the minimum roughness values for each respective profile. The profiles were calculated from points representing the whole study area with a regular grid spacing of $100 \mathrm{~km}$. A parabola was fitted to each single profile and then all the profiles were collapsed around their parabolic minima and plotted together. The red thick line represents a parabolic fit to all the data. 


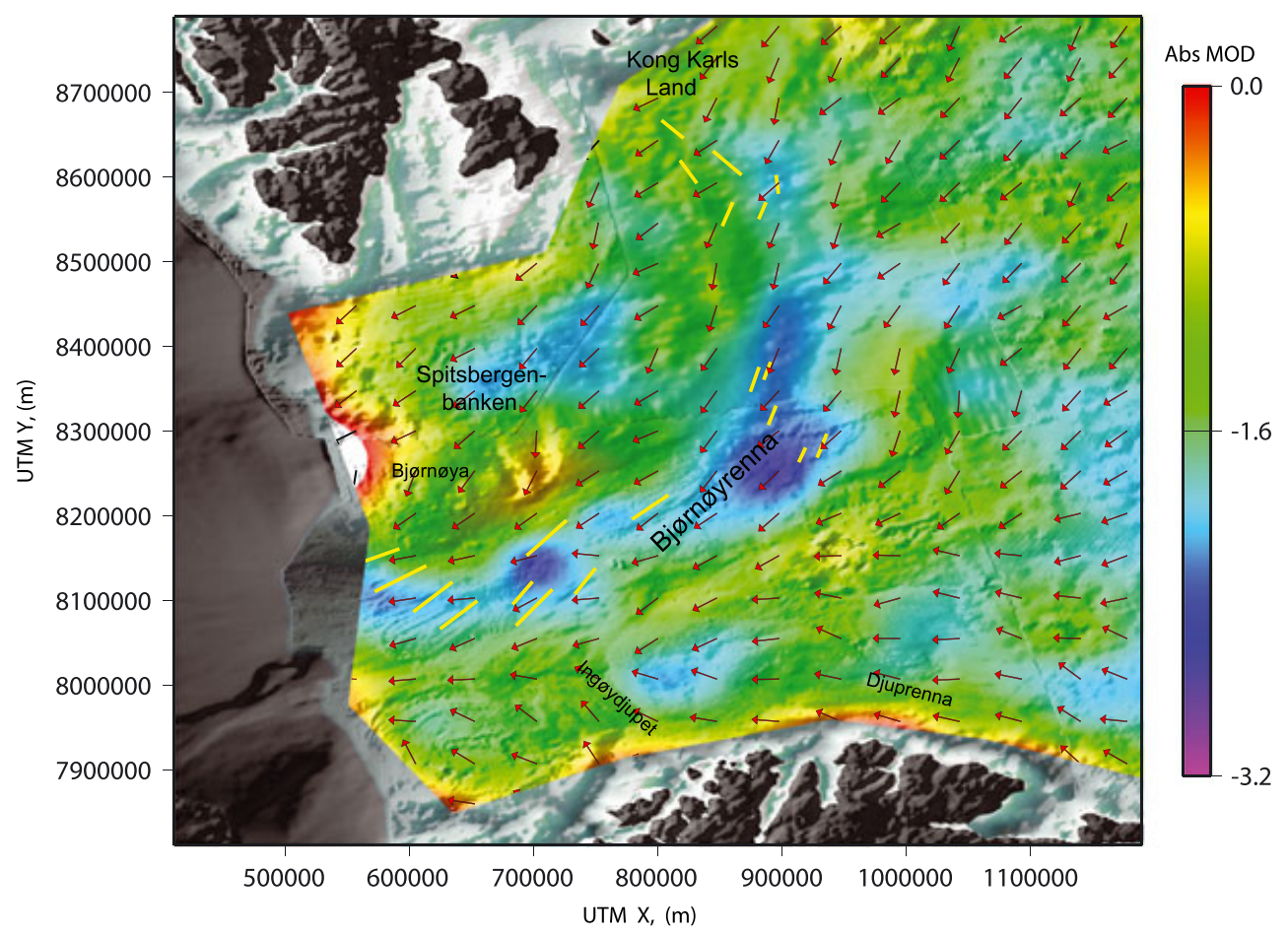

Figure 8. Map showing the spatial variation of the difference between the maximum and the minimum $\xi$ roughness (absolute MOD) depending on orientation. The colorscale shows the logarithmic power of the absolute MOD. Arrows indicate the direction of the roughness minima, and the yellow lines indicate the MSGLs from Figure 1. Both the absolute MOD and the directions of roughness minima have been averaged over an area of $50 \times 50 \mathrm{~km}^{2}$.

roughness changes only slightly with the number of datapoints used as can be seen from the cumulative integral. That is, resolving the higher frequencies better by simply adding datapoints does not result in a significant change to the roughness estimate.

[19] Figure 3a displays the resulting power spectrum for a fixed number of datapoints, $N=32$, while the size of the MW decreases from $\sim 50 \mathrm{~km}$ to the smallest possible MW $(775 \mathrm{~m})$ that our data set allowed, using the full resolution of the data set. Decreasing the MW size while keeping $N$ fixed effectively increases both the lower and the upper wave number limits of integration resulting in a different wave number spectrum for each calculation. In general, for a given location the roughness will vary depending on the size of the MW because of changes in the integration interval as well as changes in the scaling since for each MW the roughness is scaled with the length of that MW.

[20] To further investigate the effect of the MW size and how the resolution of the data affects the roughness estimates, we used a high-resolution track line running from the south of Kong Karls Land to the southwestern Bjørnøyrenna continental shelf break (Figure 1). Figure 4a displays the bathymetry profile in meters below sea level along the $750 \mathrm{~km}$ long track line, while Figure $4 \mathrm{~b}$ shows the spectral roughness for different lengths of the MW. In general, the four different roughness profiles presented here have a similar range of roughness values. However, the roughness is noticeably higher as the size of the MW decreases for the downstream half of the track line. Figure 4c shows the $\eta$ index, which accounts for horizontal irregularities. With the scaling that was introduced (equation (4)), the $\eta$ profiles all show a similar range of values, with values roughly above $10^{-1}$ having a stronger relative dominance of longer wavelengths.

[21] Figure 5 reveals the wavelength components, as defined by Table 1, of the four roughness profiles presented in Figure 4b. Splitting the integration (equation (3)) over different intervals reveals which wavelength components contribute the most to the $\xi$ roughness index. The sum of the different components for each MW length equals the total value seen in Figure $4 \mathrm{~b}$. A relative dominance of longer wavelengths corresponds with a peak in the $\eta$ index (Figure 5). The wavelength group s1, which corresponds to $600-1250 \mathrm{~m}$, is particularly dominant in the downstream half of the trough which is probably due to an increased density of iceberg ploughmarks in the area.

[22] In Figure 6a, we present four different roughness profiles from Bjørnøyrenna, all calculated with the same length of the MW but using a different number of datapoints for each estimate. The differences between the four different profiles are minimal, which can be seen as verification for the fact that 32 datapoints for each profile are adequate for roughness calculations of this type. Figure $6 \mathrm{~b}$ shows the four different $\eta$ profiles. With increasing resolution, the slope profile (equation (4)) gets progressively rougher for the lower half of the track line, resulting in lower $\eta$ values. Figure $6 \mathrm{c}$ shows the individual contributions from the different wavelength components of roughness (Table 1) for the profile with the largest distance between datapoints $(d s=1600 \mathrm{~m})$. 


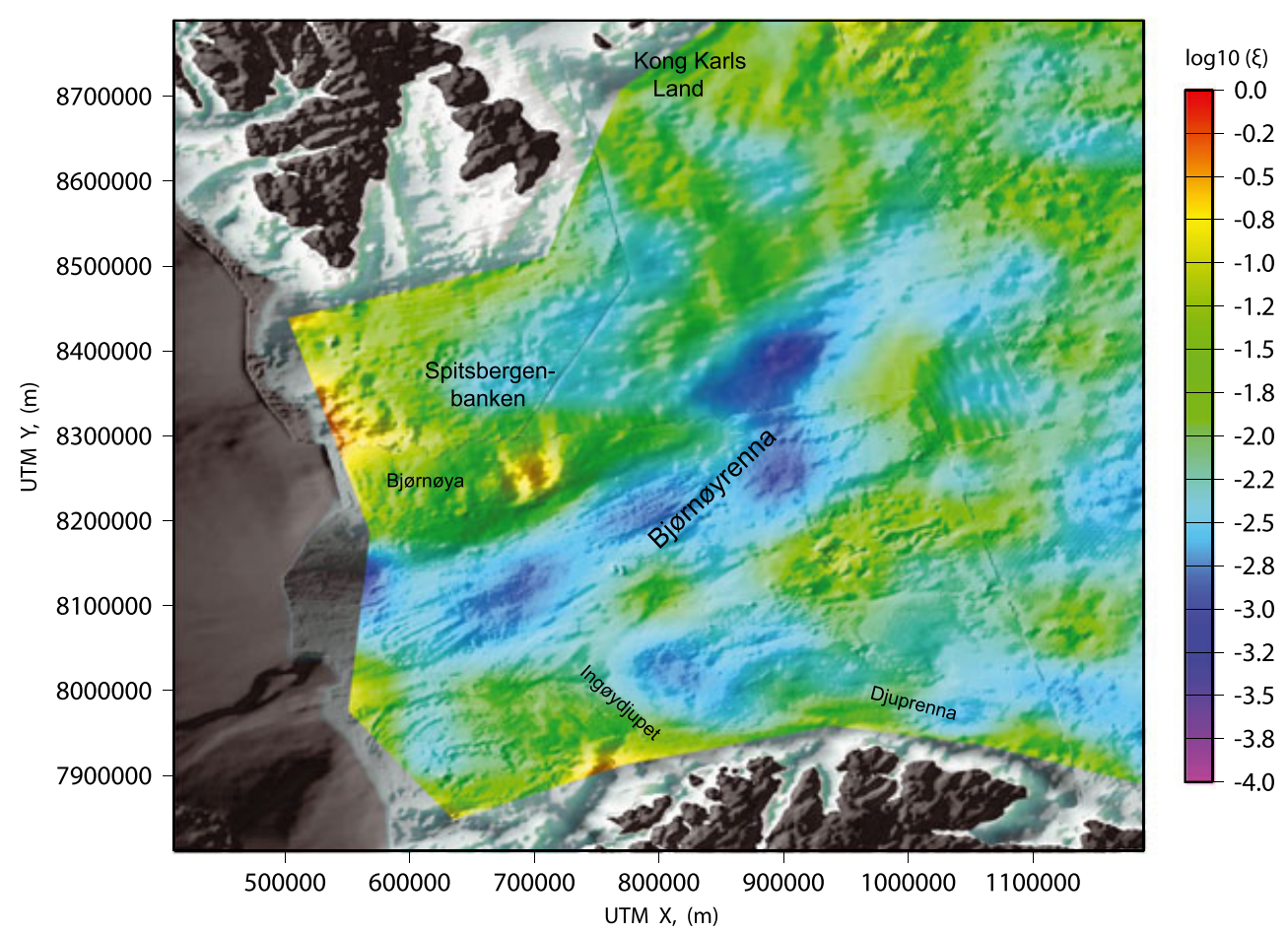

Figure 9. Map of basal roughness $(\xi)$ for the western Barents Sea. The colorscale represents the logarithmic power of the basal roughness index. This is calculated using 32 datapoints $(N)$ for each point estimation and with a distance of $1600 \mathrm{~m}$ between each datapoint $(d s)$.

\subsection{MW Orientation and Angle Dependence}

[23] The blue and the green lines in Figure 6d represent the absolute MOD and the relative MOD, respectively. The absolute MOD shows a moderate correlation with $\xi$ roughness, while the relative MOD shows a moderate anticorrelation. In both cases the correlation grows stronger with increasing wavelength.

[24] For glaciated terrains like Antarctica or Greenland, roughness estimates are usually queried along flight tracks of preimposed orientation and not necessarily in the direction of ice flow. This entails some deviation from the roughness that the ice actually experiences as the roughness is generally expected to have a minimum in the flow direction.

[25] The variation of $\xi$ roughness with orientation is presented in Figure 7 for a number of locations in the southwestern Barents Sea. The locations were chosen by overlaying a fixed $100 \mathrm{~km} \times 100 \mathrm{~km}$ grid over the region and performing the calculation at each equally spaced vertex. The locations are therefore representative of the entire study area. A parabolic curve was fitted to each individual profile because of its simple representation and single minimum, and then all profiles were plotted together, ranging from $-90^{\circ}$ to $+90^{\circ}$, with their parabolic minimum at the center. The thick red line in Figure 7 represents a best fit through all the profiles with linear regression. The roughness estimate shows a strong dependence with direction and typically a 40-fold difference between the minimum roughness value at one point and the maximum. The variation is, however, quite large and maximum values range from a few times the minimum to around 400 times the minimum. A strong angle dependence is shown for all wavelength groups, but the minimum is not always acquired at the same angle within each group, although the variation between each group is usually small.

[26] Furthermore, the calculation with the $5 \mathrm{~km}$ spacing was used in order to examine the spatial distribution of the absolute MOD, which is presented in Figure 8.

[27] By averaging the angles at which a minimum in roughness was acquired, we end up with a directional map that should resemble a map of former ice flow directions for the western Barents Sea at the time of the last glaciation. The arrows in Figure 8 indicate the averaged directions of the roughness minima. These directions were then used as a basis for the roughness map shown in Figure 9.

\section{Discussion}

\subsection{Geomorphic Features}

[28] Our results show opposing trends between the large-scale and the small-scale roughness. The large-scale roughness typically decreases until the deepest point of Bjørnøyrenna, while the small-scale roughness shows more or less a continuous increase in measured roughness toward the continental shelf break (Figure 4). We interpret this as being caused mostly by the increasing density of iceberg ploughmarks toward the shelf break. Close to the shelf break, an area of around $3000 \mathrm{~km}^{2}$ in size (Figure 1; yellow box) has been mapped for geomorphological purposes [Rüther et al., 2011], and that part of the trough has a very dense network of iceberg ploughmarks. Iceberg ploughmarks have a typical length scale of between tens of meters up to several hundred meters across the ploughmark and will therefore cause an increase in measured roughness over 
these length scales. These ploughmarks also introduce sharp bathymetry gradients which become clearer and sharper with higher resolution. These cause a decrease in the $\eta$ parameter with increasing resolution because of the increased relative importance of the shorter wavelengths (Figure 6).

[29] Several ice-marginal deposits have been identified in the area (Figure 1) [Winsborrow et al., 2010], and these are typically represented by a sharp peak in roughness, especially at longer wavelengths and by a local increase in absolute MOD (Figures 5 and 6). Figure 4 illustrates how the different roughness profiles diverge away from one another roughly $375 \mathrm{~km}$ away from the shelf break at a point which corresponds to a local minimum in elevation. Close to this point, an ice-marginal deposit has been mapped which may have been a stable grounding line position for some time during the deglaciation period. Downstream of that location, the small-scale roughness increases, especially in the "s1" wavelength group, while the longer wavelengths stay at a more or less constant low level.

[30] Three peaks in roughness are observed in Figure 5b between the $500 \mathrm{~km}$ and the $400 \mathrm{~km}$ marks that correspond to geomorphic features that have been mapped as possible ice margins (Figure 1). These have a characteristic signal of increased long wavelength roughness, and their locations can be picked out easily from roughness diagrams. Where a multibeam track line comprises the only available data, such roughness analysis might therefore give valuable information as to the whereabouts of ice-marginal deposits and possibly other geomorphic features that the track line crosses. However, more data and further analyses are necessary for verification. Both ploughmarks and ice-marginal deposits cause a change in measured roughness as compared to the roughness of the ice sheet bed at the time of the LGM. No detailed map of Holocene sediments is available for the Barents Sea, but sedimentation rates for the southwestern Barents Sea are in general thought to be quite low. A thin drape $(<2 \mathrm{~m})$ of Holocene sediments covers most of the Barents Sea [Elverhøi and Solheim, 1983] which will primarily affect roughness measurements on very small scales. Here we look at roughness on the scale of several kilometers down to tens of meters; hence, postglacial modification caused by ocean currents and marine sedimentation is therefore not considered to be an issue of significant importance.

\subsection{Effect of MW Length and Resolution}

[31] As noted earlier, an important question concerning subglacial roughness captured along RES tracks is how the roughness estimate is affected by the sampling resolution of the tracks and the length of the MW. Our results indicate that the roughness estimate is strongly dependent on the length of the MW but not so much on the sampling resolution, provided that an adequate number of datapoints has been used for each point estimation. Increasing the number of datapoints for each roughness estimation, and thereby increasing the upper wave number limit for integration, does not lead to a significantly different roughness estimate for a fixed length of the MW (Figures 2, 3, and 6). In our case, however, it does result in a lower $\eta$ index as the slope profile appears rougher with increasing resolution. The $\xi$ roughness index remains unchanged, but the effect is seen clearly on the power spectrum of the slope profile $\left(\xi_{s l}\right)$, causing it to become greater such that consequently the ratio $(\eta)$ between the two drops. This is not representative for a presently glaciated area though, as a large part of the change is due to the presence of iceberg ploughmarks. On the other hand, this shows that roughness analysis of this type can be a valuable tool in the interpretation of subglacial landforms.

[32] The $\eta$ parameter proves to be a very convenient way of continuously expressing the horizontal irregularities, although similar information can be acquired by looking at the different contributions from the different wavelength groups. In general, an increase in the $\eta$ index results from an increased relative importance of the longer wavelengths, as can be seen from Figures 4, 5, and 6. Here the $\eta$ index is small where the small-scale roughness is dominant and large when large-scale roughness is dominant.

\subsection{Orientation Dependence}

[33] Bed elevation and ice thickness data are acquired along flight tracks, usually in straight lines and not necessarily in the direction of ice flow. Although it is tempting to use all bed elevation data for roughness studies, our results show that changing the orientation of a single elevation profile extracted for roughness measurements can significantly change the calculated spectral roughness for that point in space. The relative difference between the minimum and the maximum roughness depending on orientation can be up to several orders of magnitude (Figure 7). This angle dependence is observed for all wavelength groups, as well as for the $\eta$ index, indicating increased dominance of longer wavelengths in the across flow direction as compared to along flow. Curves showing roughness as a function of orientation can also have multiple minima, possibly related to changes in ice flow direction in the past. For deglaciated areas like the Barents Sea, many geomorphological features reveal the direction of former ice flow, like mega-scale glacial lineations (MSGLs) and drumlins. These can be compared to the orientations for which a minimum in roughness is acquired. In Figure 8, several MSGLs are presented that have been mapped and associated with various retreat stages of the BSIS [Winsborrow et al., 2010]. Each retreat stage can be associated with a different time period and a different ice sheet configuration and thus possibly with somewhat different ice flow directions for each stage. The apparent mismatch between the directions of roughness minima and the MSGLs is thought to stem from the fact that roughness on this spatial scale is likely to reflect the integrated effect of erosion and deposition over longer time scales, whereas the MSGLs can only be related to flow directions at the time of formation. Part of the high-resolution data used for this study also contained several MSGLs (Figure 1; red lines, yellow box), the orientation of which had a direction that differed only by $2^{\circ}$ from the estimated past flow direction based on roughness analysis. In this case the MW was chosen to be as large as the high-resolution databox allowed $(20 \mathrm{~km})$ in order to minimize the effect of the MSGLs on the spectral roughness. A smaller MW with this data set would have resulted in an even stronger contrast between a flow-parallel and a flow-perpendicular direction so that even over larger spatial scales, the bed in the flow direction is preferentially smoothed past a threshold sufficient for it to become measurable by the spectral roughness method. Our data also show a moderate correlation between the strength of the absolute orientation dependence (abs. MOD) and the 
$\xi$ roughness parameter as well as a moderate anticorrelation between the relative MOD and $\xi$, with the correlation growing stronger with increasing wavelength (Figures 6, 8, and 9).

\subsection{Geographical Distribution of Roughness}

[34] In general, for long MW, the roughness is smaller in Bjørnøyrenna than in adjacent areas (Figure 9) as expected for an area of fast flow and high rates of basal erosion [Bingham and Siegert, 2007]. A zone of low roughness is also seen in Djuprenna while Ingøydjupet has considerably higher roughness compared with the other troughs in the study area. In both of these locations, ice streams also operated (Figure 1). Spitsbergenbanken shows the highest roughness values of the whole study area. This is a submarine bank area, with typical water depths of between $40 \mathrm{~m}$ and $60 \mathrm{~m}$, and it is one of the shallowest areas of the Barents Sea. It has experienced very little glacial erosion in the last 0.7 Ma compared with the troughs [Laberg et al., 2011], and ice flow over it is likely to have been considerably slower.

[35] Similar roughness calculations have been completed for various, previously marine-inundated areas in Antarctica using RES data and MWs of between $1 \mathrm{~km}$ and $100 \mathrm{~km}$. The roughness values that we get for the southwestern Barents Sea range from $10^{-4}$ to $10^{-1}$ for all lengths of the MW, consistent with those found beneath both Pine Island Glacier (PIG) [Rippin et al., 2011] and in the Siple Coast region [Siegert et al., 2004], where the low roughness values have been considered as a first-order indicator of a previous marine inundation and sediment drape [Bingham and Siegert, 2009]. The southwestern Barents Sea shows somewhat higher roughness values than the PIG catchment even though the roughness values from the PIG area have not always been calculated in the flow direction and also with a different length of the MW. These three geographically distinct areas, all previously marine inundated in the past, share a similar roughness signature.

\section{Conclusions}

[36] Using bathymetry data from shipborne 2-D and 3-D seismics and multibeam sonar, the subglacial roughness of a Quaternary glaciated terrain has, for the first time, been quantified. This yields roughness estimates of higher resolution, greater coverage, and at a wider range of scales, than are possible with most existing Antarctic radio echo sounding data sets. The roughness index varies insignificantly with resolution for a fixed length of the moving window (MW) and with constant scaling, but both roughness parameters show considerably more variation as the length of the MW changes. This implies that roughness measurements from different studies are not directly comparable unless calculated with similar lengths of the MW. A strong dependence on orientation is observed for both roughness parameters, as well as for all wavelength groups. Even a small deviation, on the order of a few degrees, can cause a significant change in estimated roughness, and care must be taken when interpreting such roughness estimates for track lines that are not in the flow direction. Rougher areas typically have a stronger absolute orientation dependence and a weaker relative one.

[37] Here we have provided the first confirmation that a Quaternary glaciated region of the world that has also experienced several cycles of glaciations in the past interspersed with interglacial marine inundations [Svendsen et al., 2004a], much like the Siple Coast region or Pine Island Glacier, has imprinted a similar roughness signature [Bingham and Siegert, 2009; Rippin et al., 2011]. This provides promise that as more roughness analysis on glacially defined surfaces emerges, it may be possible to develop a quantitative scheme to characterize subglacial landscapes in the future.

[38] Acknowledgments. Funding for this work came from the Research Council of Norway (RCN), Statoil, Det Norske ASA, and BG group Norway (grant 200672) to the PetroMaks project Glaciations in the Barents Sea area (GlaciBar) and from the Research School in Arctic Marine Geology and Geophysics (AMGG) at the University of Tromsø. This is also a contribution to the Centre of Excellence: Arctic Gas Hydrate, Environment and Climate (CAGE) funded by RCN (grant 223259). We thank the captain and crew of R/V Helmer Hanssen (previously Jan Mayen), and Steinar Iversen for collecting and processing of the data. We would also like to thank R.G. Bingham, the associate editor M.J. Bentley, and one anonymous reviewer for their constructive reviews that greatly improved the manuscript.

\section{References}

Anderson, J. B., S. S. Shipp, A. L. Lowe, J. S. Wellner, and A. B. Mosola (2002), The Antarctic Ice Sheet during the Last Glacial Maximum and its subsequent retreat history: A review, Quat. Sci. Rev., 21(1), 49-70.

Andreassen, K., and M. Winsborrow (2009), Signature of ice streaming in Bjørnøyrenna, Polar North Atlantic, through the Pleistocene and implications for ice-stream dynamics, Ann. Glaciol., 50(52), 17-26.

Andreassen, K., J. S. Laberg, and T. O. Vorren (2008), Seafloor geomorphology of the SW Barents Sea and its glaci-dynamic implications, Geomorphology, 97(1-2), 157-177.

Bingham, R. G., and M. J. Siegert (2007), Radar-derived bed roughness characterization of Institute and Möller ice streams, West Antarctica, and comparison with Siple Coast ice streams, Geophys. Res. Lett., 34, L21504, doi:10.1029/2007GL031483.

Bingham, R. G., and M. J. Siegert (2009), Quantifying subglacial bed roughness in Antarctica: Implications for ice-sheet dynamics and history, Quat. Sci. Rev., 28(3-4), 223-236.

Bingham, R. G., M. J. Siegert, D. A. Young, and D. D. Blankenship (2007), Organized flow from the South Pole to the Filchner-Ronne ice shelf: An assessment of balance velocities in interior East Antarctica using radio echo sounding data, J. Geophys. Res., 112, F03S26, doi:10.1029/2006JF000556.

Boulton, G. S. (1979), Processes of glacier erosion on different substrata, J. Glaciol., 23(89), 15-38.

Brigham, E. O. (1988), The fast Fourier transform and its applications, IEEE Trans. Educ., 12(1), 27-34.

Elverhøi, A., and A. Solheim (1983), The Barents Sea ice sheet: A sedimentological discussion, Polar Res., 1(1), 23-42.

Evans, J., J. A. Dowdeswell, C. Ó Cofaigh, T. J. Benham, and J. B. Anderson (2006), Extent and dynamics of the West Antarctic ice sheet on the outer continental shelf of Pine Island bay during the last glaciation, Mar. Geol., 230(1), 53-72.

Fowler, A. C. (1979), A mathematical approach to the theory of glacier sliding, J. Glaciol., 23, 131-141.

Fowler, A. C. (1981), A theoretical treatment of the sliding of glaciers in the absence of cavitation, Philos. Trans. R. Soc. London, Ser. A, 298(1445), $637-681$.

Gudmundsson, G. H. (1997a), Basal-flow characteristics of a non-linear flow sliding frictionless over strongly undulating bedrock, J. Glaciol., 43(143), 80-89.

Gudmundsson, G. H. (1997b), Basal-flow characteristics of a linear flow sliding frictionless over small bedrock undulations, J. Glaciol., 43(143), $71-79$.

Hubbard, B., M. J. Siegert, and D. McCarroll (2000), Spectral roughness of glaciated bedrock geomorphic surfaces: Implications for glacier sliding, J. Geophys. Res., 105(B9), 21,295-21,303.

Jakobsson, M., R. Macnab, L. Mayer, R. Anderson, M. Edwards, J. Hatzky, H. W. Schenke, and P. Johnson (2008), An improved bathymetric portrayal of the Arctic Ocean: Implications for ocean modeling and geological, geophysical and oceanographic analyses, Geophys. Res. Lett., 35, L07602, doi:10.1029/2008GL033520.

Kamb, B. (1970), Sliding motion of glaciers: Theory and observation, Rev. Geophys., 8(4), 673-728. 


\section{GUDLAUGSSON ET AL.: SUBGLACIAL ROUGHNESS OF THE FORMER BSIS}

Laberg, J. S., K. Andreassen, and T. O. Vorren (2011), Late Cenozoic erosion of the high-latitude southwestern Barents Sea shelf revisited, Geol. Soc. Am. Bull., 124(1-2), 77-88.

Li, X., B. Sun, M. J. Siegert, R. G. Bingham, X. Tang, D. Zhang, X. Cui, and X. Zhang (2010), Characterization of subglacial landscapes by a twoparameter roughness index, J. Glaciol., 56(199), 831-836.

Nye, J. F. (1970), Glacier sliding without cavitation in a linear viscous approximation, Proc. R. Soc. London, Ser. A, 315(1522), 381-403.

Rippin, D. M., D. G. Vaughan, and H. F. J. Corr (2011), The basal roughness of Pine Island Glacier, West Antarctica, J. Glaciol., 57(201), 67-76.

Rüther, D. C., R. Mattingsdal, K. Andreassen, M. Forwick, and K. Husum (2011), Seismic architecture and sedimentology of a major grounding zone system deposited by the Bjørnøyrenna Ice Stream during Late Weichselian deglaciation, Quat. Sci. Rev., 30(19), 2776-2792.

Shepard, M. K., B. Campbell, M. H. Bulmer, T. G. Farr, L. R. Gaddis, and J. J. Plaut (2001), The roughness of natural terrain: A planetary and remote sensing perspective, J. Geophys. Res., 106, 32,777-32,795.

Siegert, M. J., J. Taylor, A. J. Payne, and B. Hubbard (2004), Macro-scale bed roughness of the Siple Coast ice streams in West Antarctica, Earth Surf. Processes Landforms, 29(13), 1591-1596.
Siegert, M. J., J. Taylor, and A. J. Payne (2005), Spectral roughness of subglacial topography and implications for former ice-sheet dynamics in East Antarctica, Global Planet. Change, 45(1), 249-263.

Svendsen, J. I., V. Gataullin, J. Mangerud, and L. Polyak (2004a), The glacial history of the Barents and Kara Sea region, Dev. Quat. Sci., 2, 369-378.

Svendsen, J. I., et al. (2004b), Late Quaternary ice sheet history of northern Eurasia, Quat. Sci. Rev., 23(11), 1229-1271.

Taylor, J., M. J. Siegert, A. J. Payne, and B. Hubbard (2004), Regional-scale bed roughness beneath ice masses: Measurement and analysis, Comput. Geosci., 30(8), 899-908.

Vorren, T. O., M. Hald, and E. Lebesbye (1988), Late Cenozoic environments in the Barents Sea, Paleoceanography, 3(5), 601-612.

Weertman, J. (1957), On the sliding of glaciers, J. Glaciol., 3(21), 33-38.

Winsborrow, M., K. Andreassen, G. D. Corner, and J. S. Laberg (2010), Deglaciation of a marine-based ice sheet: Late Weichselian palaeo-ice dynamics and retreat in the southern Barents Sea reconstructed from onshore and offshore glacial geomorphology, Quat. Sci. Rev., 29(3), 424-442. 